\title{
The Somatostatin Analog ${ }^{188}$ Re-P2045 Inhibits the Growth of AR42J Pancreatic Tumor Xenografts
}

\author{
Carol A. Nelson ${ }^{1,2}$, Michael T. Azure ${ }^{3}$, Christopher T. Adams², and Kurt R. Zinn ${ }^{3}$ \\ ${ }^{I}$ Translational Medicine Consulting, Westford, Massachusetts; ${ }^{2}$ Department of Research and Development, Andarix Pharmaceuticals, \\ Watertown, Massachusetts; and ${ }^{3}$ Department of Radiology, University of Alabama at Birmingham, Birmingham, Alabama
}

\begin{abstract}
P2045 is a peptide analog of somatostatin with picomolar affinity for the somatostatin receptor subtype 2 (SSTR2) upregulated in some pancreatic tumors. Studies were conducted in rat AR42J pancreatic tumor xenograft mice to determine whether ${ }^{188} \mathrm{Re}-\mathrm{P} 2045$ could inhibit the growth of pancreatic cancer in an animal model. Methods: ${ }^{188} \mathrm{Re}-\mathrm{P} 2045$ was intravenously administered every $3 \mathrm{~d}$ for $16 \mathrm{~d}$ to nude mice with AR42J tumor xenografts that were approximately $20 \mathrm{~mm}^{3}$ at study initiation. Tumor volumes were recorded throughout the dosing period. At necropsy, all tissues were assessed for levels of radioactivity and evaluated for histologic abnormalities. Clinical chemistry and hematology parameters were determined from terminal blood samples. The affinity of nonradioactive ${ }^{185 / 187}$ Re-P2045 for somatostatin receptors was compared in human $\mathrm{NCl}-\mathrm{H} 69$ and rat AR42J tumor cell membranes expressing predominantly SSTR2. Results: In the 1.85- and 5.55-MBq groups, tumor growth was inhibited in a dose-dependent fashion. In the 11.1-MBq group, tumor growth was completely inhibited throughout the dosing period and for $12 \mathrm{~d}$ after the last administered dose. The radioactivity level in tumors $4 \mathrm{~h}$ after injection was 10 percentage injected dose per gram, which was 2-fold higher than in the kidneys. ${ }^{188}$ Re-P2045 was well tolerated in all dose groups, with no adverse clinical, histologic, or hematologic findings. The nonradioactive ${ }^{185 / 187} \mathrm{Re}-\mathrm{P} 2045$ bound more avidly $(0.2 \mathrm{nM})$ to SSTR2 in human than rat tumor membranes, suggesting that these studies are relevant to human studies. Conclusion: ${ }^{188} \mathrm{Re}-\mathrm{P} 2045$ is a promising therapeutic candidate for patients with somatostatin receptor-positive cancer.
\end{abstract}

Key Words: somatostatin; AR42J pancreatic tumor; radiotherapeutic; neuroendocrine; pancreas

J Nucl Med 2014; 55:2020-2025

DOI: 10.2967/jnumed.114.140780

\section{$\mathbf{S}$} the no nomatotropin, glucagon, insulin, thyrotropin, and gastrin (1). Secretion of these hormones from neuroendocrine tumors can lead to a life-threatening hormonal imbalance that can be inhibited by SST. However, SST is rapidly inactivated by peptidases in vivo,

Received Apr. 13, 2014; revision accepted Sep. 11, 2014.

For correspondence or reprints contact: Carol A. Nelson, Andarix Pharmaceuticals and Translational Medicine Consulting, 18 Maple St., Westford, MA 01886.

E-mail: pharmacologyconsultants@gmail.com

Published online Oct. 30, 2014.

COPYRIGHT (c) 2014 by the Society of Nuclear Medicine and Molecular Imaging, Inc. with a circulating half-life of less than 2 min that precludes its development as a therapeutic agent. Thus, SST analogs (SSTAs) with enhanced biologic stability have been synthesized and approved for the neuroendocrine tumor therapy (2).

The potent inhibitory actions of SSTA are initiated by their high-affinity binding to the G-protein-coupled SST receptor (SSTR). SSTR subtype 2 (SSTR2), 1 of 5 cloned receptor subtypes, is the most commonly overexpressed subtype in pancreatic tumors $(2,3)$. The expression of SSTR2 has also been reported in tumor neovasculature but not in normal vasculature (4). Tumor expression of SSTR provides the basis for detection and staging of disease by the administration of SSTA coupled to $\gamma$-emitting radioisotopes followed by scintigraphy (5). For example, pentreotide ([diethylenetriamine pentaacetic acid] octreotide) labeled with ${ }^{111} \mathrm{In}$ is approved for the detection of neuroendocrine tumors (6), and depreotide labeled with ${ }^{99 \mathrm{~m}} \mathrm{Tc}$ was previously approved for the detection of lung cancer (7).

Cytotoxic moieties have been coupled to peptides and antibodies and thereby targeted to upregulated receptors on tumors $(1,8)$. The peptide approach has some advantages. Peptides are smaller and can diffuse more readily into tumor tissue. Furthermore, peptides are less likely to produce an immune response and can be transported into tumor cells by receptor-mediated endocytosis. They are also cleared rapidly from the circulation, resulting in decreased whole-body exposure. As such, SSTA labeled with cytotoxic isotopes have been used to deliver radiotherapeutics to tumors overexpressing SSTR (2,9). For example, clinical trials have been conducted with the SSTA ${ }^{90}$ Y-DOTATOC and ${ }^{177}$ Lu-DOTATATE for the treatment of neuroendocrine tumors (10). Another SSTA, P2045 labeled with ${ }^{188} \mathrm{Re}$, was evaluated in a clinical trial for lung cancer (9) in which there was a good correlation between the visualization of lung tumors with ${ }^{99 \mathrm{~m} T c-P 2045}$ and ${ }^{188} \mathrm{Re}-\mathrm{P} 2045$ uptake (11).

Neuroendocrine tumors of the pancreas, gut, and lung overexpress SSTR $(12,13)$, and for this reason ${ }^{188}$ Re-P2045 may be an effective therapy for this class of tumors. The studies herein describe proof of concept for ${ }^{188} \mathrm{Re}-\mathrm{P} 2045$ therapy in the AR42J rat pancreatic tumor xenograft nude mouse.

\section{MATERIALS AND METHODS}

\section{${ }^{188}$ Re-P2045 and Control Preparation}

A lyophilized mix of P2045 peptide trifluoroacetate (53 $\mu \mathrm{g}$ of free peptide), sodium $\alpha$-D-glucoheptonate dihydrate $(25 \mathrm{mg})$, edetate disodium hydrate $(100 \mu \mathrm{g})$, and $\mathrm{SnCl}_{2}(850 \mu \mathrm{g})$ was reconstituted with 1.1 $\mathrm{GBq}$ of Sodium Perrhenate ${ }^{188} \mathrm{Re}$ from a generator (Oak Ridge National Laboratories) and boiled for $15 \mathrm{~min}$. Lyophilized gentisic acid $(20 \mathrm{mg})$ and ascorbic acid $(10 \mathrm{mg})$ were reconstituted with saline and added to the cooled ${ }^{188} \mathrm{Re}-\mathrm{P} 2045$ solution. Peptide control saline was added in place of ${ }^{188} \mathrm{Re}$. Vehicle was decayed generator eluate. 


\section{Quality Analysis of ${ }^{188}$ Re-P2045}

${ }^{188} \mathrm{Re}-\mathrm{P} 2045$ was determined using instant thin-layer chromatography silica gel (Gelman) developed in saturated saline, 1:1 methanol:1.0 M ammonium acetate, and methyl ethyl ketone.

For high-performance liquid chromatography (HPLC), ${ }^{188}$ Re-P2045 was eluted on a linear gradient $50 \%-54 \%$ A to B over $32 \mathrm{~min}$ on a Zorbax 300SB reversed-phase column (880995-902; Rockland Technologies). Mobile phase A was $0.1 \%$ trifluoroacetic acid in water. Mobile phase B was $0.1 \%$ trifluoroacetic acid in $90 / 10$ methanol/water.

\section{${ }^{88}$ Y-DOTATOC Preparation}

${ }^{88} \mathrm{YCl}_{3}(555 \mathrm{MBq}$; NEN) in $12 \mu \mathrm{L}$ of $0.05 \mathrm{M} \mathrm{HCl}$ was added to $10 \mu \mathrm{g}$ of DOTATOC (Diatide) in $1.0 \mathrm{~mL}$ of saline with $0.5 \mu \mathrm{L}$ of $1 \mathrm{mM}$ $\mathrm{YCl}_{3}$. The vial was boiled for $25 \mathrm{~min}$, cooled to room temperature, and passed through a QMA Light Sep-Pak column (Waters). The column was rinsed with $1.0 \mathrm{~mL}$ of ammonium acetate and $2.0 \mathrm{~mL}$ of phosphatebuffered saline and eluted with a solution of $50 \%$ ethanol. Solvent was removed by vacuum, and ${ }^{88}$ Y-DOTATOC was reconstituted with saline.

\section{5/187Re-P2045 Preparation}

Nonradioactive ${ }^{185 / 187} \mathrm{Re}-\mathrm{P} 2045$ was prepared by reacting peptide with a 1.5-fold molar excess of $\mathrm{Bu}_{4} \mathrm{NReOCl}_{4}$ in anhydrous dimethylformamide at room temperature (13). Products were isolated by reversed-phase HPLC.

\section{Binding Studies}

NCI-H69 or AR42J cell membranes were incubated with ${ }^{125} \mathrm{I}$ (Tyr11)-SST14 (NEN) at $37^{\circ} \mathrm{C}(\mathrm{pH} \mathrm{7.4)}$ in the presence of test peptides as described previously (14). Membrane-bound ${ }^{125}$ I-SST was isolated by filtration. Nonspecific binding was determined in the presence of excess SST14 (10 $\mu \mathrm{M}$; Sigma). The inhibition of specific binding was calculated at 6 concentrations of test peptide $(0.01-100 \mathrm{nM})$ and plotted using a Stineman function (Kaleidagraph 4.5; Synergy Software) from which the $\mathrm{IC}_{50}$ values were calculated. $\left(\mathrm{IC}_{50}\right.$ value is defined as the concentration of agent required to inhibit the specific binding of ${ }^{125} \mathrm{I}-$ SST14 by $50 \%$.)

\section{Animal Model}

University of Alabama at Birmingham's institutional animal care and use committee approved all animal studies. Washed cells were mixed with Matrigel (Collaborative Biochemical Products) and injected subcutaneously into outbred athymic nude mice Crl:NU/ NU-nuBR (Charles River). Resulting tumor xenografts were minced, combined with a 50:50 mix of Matrigel and medium, and injected into the right flank of study mice. After $3 \mathrm{wk}$, mice with uniform tumor volumes $\left(\approx 20 \mathrm{~mm}^{3}\right)$ were selected for study.

\section{Study Design}

The study design is outlined in Table 1 . Tumor-bearing mice were divided into 10 groups. There were 6 multiple-dose therapeutic study groups (1-6) and 4 single-dose biodistribution study groups (7-10). Groups $1-5(n=10)$ received an intravenous injection $(100 \mu \mathrm{L})$ on study days $0,3,6,9,12$, and 16 : decayed ${ }^{188} \mathrm{~W} /{ }^{188} \mathrm{Re}$ generator eluate (group 1), $530 \mathrm{ng}$ of nonradiolabeled P2045 (group 2), $1.85 \mathrm{MBq}$ of ${ }^{188} \mathrm{Re}-\mathrm{P} 2045$ containing $88 \mathrm{ng}$ of peptide (group 3), $5.5 \mathrm{MBq}$ of ${ }^{188} \mathrm{Re}-$ P2045 containing $265 \mathrm{ng}$ of peptide (group 4), or $11.1 \mathrm{MBq}$ of ${ }^{188} \mathrm{Re}-$ P2045 containing $530 \mathrm{ng}$ of P2045 peptide (group 5). A single dose of ${ }^{88}$ Y-DOTATOC was administered to groups $6(22.2 \mathrm{MBq}$, intraperitoneally), 9 (11.1 MBq, intravenously), and 10 (11.1 MBq, intravenously). Groups 7 and 8 received a single dose of ${ }^{188}$ Re-P2045 (9.25 MBq). The dose administered to each animal was quantified in syringes before and after injection using a dose calibrator (Atomlab 100; Biodex Medical Systems). Therapeutic treatment groups 1-4 were sacrificed on study day 16. Group 5 (11.1 MBq of ${ }^{188}$ Re-P2045) was observed for an additional $12 \mathrm{~d}$ without dosing and sacrificed on study day 28 . A single technician measured tumor length, width, and height using Veirner calipers (Fisher Scientific) in a masked fashion.

\section{Biodistribution}

The biodistribution of radioactivity was determined in groups 3-5 and 7-10. On the last study day, mice in groups 3, 4, and 5 received an intravenous dose of $7.4 \mathrm{MBq}$ of ${ }^{188} \mathrm{Re}-\mathrm{P} 2045$ and were sacrificed $4 \mathrm{~h}$ after injection. Mice in groups 7 and 8 received an intravenous dose of $9.25 \mathrm{MBq}$ of ${ }^{188} \mathrm{Re}-\mathrm{P} 2045$ and were sacrificed 4 and $24 \mathrm{~h}$ after injection. Mice in groups 9 and 10 received a dose of $7.4 \mathrm{MBq}$ of ${ }^{88}$ Y-DOTATOC and were sacrificed 4 and $24 \mathrm{~h}$ after injection. Sacrifice was by cardiac puncture exsanguination under isoflurane anesthesia. Tissues were fixed in $10 \%$ formalin and counted for radioactivity (Minaxi $\gamma$ Auto-Gamma 5000 series $\gamma$ counter; Packard). All counts per minute data were corrected for radioactive decay using calibrated standards.

\section{Imaging Studies}

Three mice from group 8 were imaged with an Anger Sigma 410 Radioisotope Gamma Camera (Ohio Nuclear) equipped with a pinhole collimator (model PHW) at 4 and $24 \mathrm{~h}$ after injection.

\section{Clinical Observations, Necropsy, Hematology, and Histopathology}

Blood was collected in ethylenediaminetetraacetic acid. Serum was collected without anticoagulant. All tissues were examined during necropsy for gross abnormalities. Tissues were fixed in $10 \%$ formalin, embedded in paraffin, sectioned at $5 \mu \mathrm{m}$, and stained with hematoxylin and eosin. A single tumor section from each animal was used to determine

TABLE 1

Design of Repeated-Dose Study in AR42J Tumor Mice

\begin{tabular}{|c|c|c|c|c|c|}
\hline Group & No. of animals per group & No. of doses & Treatment & Route & End time \\
\hline 1 & 10 & 6 & Decayed generator eluate & Intravenous & $16 d$ \\
\hline 2 & 10 & 6 & 530 ng of nonradiolabeled P2045 & Intravenous & $16 d$ \\
\hline 3 & 10 & 6 & $1.85 \mathrm{MBq}$ of ${ }^{188} \mathrm{Re}-\mathrm{P} 2045$ & Intravenous & $16 d$ \\
\hline 4 & 10 & 6 & $5.55 \mathrm{MBq}$ of ${ }^{188} \mathrm{Re}-\mathrm{P} 2045$ & Intravenous & $16 d$ \\
\hline 5 & 10 & 6 & 11.1 MBq of ${ }^{188} \mathrm{Re}-\mathrm{P} 2045$ & Intravenous & $28 d$ \\
\hline 6 & 7 & 1 & 22.2 MBq of ${ }^{88} \mathrm{Y}$-DOTATOC & Intraperitoneal & $16 d$ \\
\hline 7 & 5 & 1 & $9.25 \mathrm{MBq}$ of ${ }^{188} \mathrm{Re}-\mathrm{P} 2045$ & Intravenous & $4 \mathrm{~h}$ \\
\hline 8 & 5 & 1 & $9.25 \mathrm{MBq}$ of ${ }^{188} \mathrm{Re}-\mathrm{P} 2045$ & Intravenous & $24 \mathrm{~h}$ \\
\hline 9 & 5 & 1 & 11.1 MBq of ${ }^{88} \mathrm{Y}$-DOTATOC & Intravenous & $4 \mathrm{~h}$ \\
\hline 10 & 5 & 1 & 11.1 MBq of ${ }^{88} \mathrm{Y}$-DOTATOC & Intravenous & $24 \mathrm{~h}$ \\
\hline
\end{tabular}


the area of necrotic tissue with Image-Pro Plus software (version 3.0) with a Hitachi single-chip camera mounted on an Olympus AH-1 microscope. Calibration was performed using neutral-buffered salinetraceable stage micrometers. A board-certified pathologist graded all tissue samples in a masked fashion.

\section{Statistical Analysis}

Tumor volumes were compared using ANOVA, followed by Dunett test to compare each treatment group with the vehicle control group (Graphpad Instat, version 3; GraphPad Software).

\section{RESULTS}

\section{Radiochemical Purity of ${ }^{188}$ Re-P2045}

The radiochemical purity of the ${ }^{188} \mathrm{Re}-\mathrm{P} 2045$ determined from instant thin-layer chromatography and HPLC was greater than $89 \%$ for all ${ }^{188} \mathrm{Re}-\mathrm{P} 2045$ solutions used in the study (Supplemental Table 1; supplemental materials are available at http://jnm.snmjournals. org).

\section{Purity of ${ }^{185 / 187}$ Re-P2045}

The purity of ${ }^{185 / 187} \mathrm{Re}-\mathrm{P} 2045$ was greater than $95 \%$ by HPLC.

\section{Binding Studies}

P2045 and its nonradioactive oxo-rhenium complex, ${ }^{185 / 187} \mathrm{Re}-$ P2045, bound with picomolar affinity to SSTR in the rat AR42J and human NCI-H69 tumor cell membranes (Table 2). The $\mathrm{IC}_{50}$ in AR42J and NCI-H69 membranes was 0.43 and $0.2 \mathrm{nM}$, respectively. The $\mathrm{IC}_{50}$ of the nonradioactive rhenium complex was $0.50 \mathrm{nM}$ in AR42J and $0.23 \mathrm{nM}$ in NCI-H69 cell membranes. The standard errors were less than $40 \%$ of the mean for all $\mathrm{IC}_{50}$ values. The $\mathrm{IC}_{50}$ values for P2045 peptide and ${ }^{185 / 187}$ Re-P2045 are similar to that of native SST $(0.2 \mathrm{nM})$ in NCI-H69 human small cell lung cancer membranes.

\section{Inhibition of Tumor Growth}

The mean tumor volumes are presented in Supplemental Table 2 and Figure 1. The tumor growth in the P2045 peptide control mice was not significantly different from the decayed eluate controls. However, there was a dose-related delay in tumor growth in the ${ }^{188} \mathrm{Re}-\mathrm{P} 2045-$ treated mice relative to the generator eluate controls. Statistically significant differences in tumor volumes were observed $6 \mathrm{~d}$ after the first injection when the tumors in the highdose ${ }^{188} \mathrm{Re}-\mathrm{P} 2045$ group were smaller than those in the decayed eluate control group $(P<0.05)$. Nine days after the first injection, all ${ }^{188} \mathrm{Re}-\mathrm{P} 2045$ treatment groups showed a significant decrease in

TABLE 2

$\mathrm{IC}_{50}$ Values for Inhibition of ${ }^{125} \mathrm{I}-\mathrm{SST}-\mathrm{Specific}$ Binding to AR42J Rat Pancreatic and NCl-H69 Human Lung Cancer Cell Membranes

\begin{tabular}{lcc}
\hline \multirow{2}{*}{ Peptide } & \multicolumn{2}{c}{$\mathrm{IC}_{50}(\mathrm{nM})^{\star}$} \\
\cline { 2 - 3 } & AR42J Rat & $\mathrm{NCl}-\mathrm{H} 69$ Human \\
\hline SST14 & $0.15 \pm 0.03$ & $0.17 \pm 0.07$ \\
P2045 & $0.43 \pm 0.19$ & $0.20 \pm 0.04$ \\
$185 / 187$ Re-P2045 & $0.50 \pm 0.16$ & $0.23 \pm 0.1$ \\
Octreotide & $1.0 \pm 0.04$ & $1.1 \pm 0.06$ \\
\hline
\end{tabular}

*Major SSTR subtype in these tumor cell lines is SSTR2. tumor growth $(P<0.05,0.05$, and 0.01 in the low-, medium-, and high-dose groups, respectively). Thirteen days after the first injection, the tumor volumes in the low-, medium-, and high-dose groups were 91,44 , and $13 \mathrm{~mm}^{3}(P<0.01)$, respectively, whereas the tumor volume in the eluate control group was $318 \mathrm{~mm}^{3}$. In the high-dose group, there was slight regression in mean tumor volume observed over the dosing period, although this was not statistically significant. Tumor growth in the ${ }^{88}$ Y-DOTATOC-treated mice was also inhibited.

All mice were sacrificed on study day 16 or earlier except for the high-dose ${ }^{188} \mathrm{Re}$ group. The mice in this group were followed for an additional $12 \mathrm{~d}$ with no dosing to determine the duration of the therapeutic effect. The mean tumor volume did not increase significantly until $12 \mathrm{~d}$ after the last dose (study day 28).

\section{Biodistribution}

The biodistribution of ${ }^{188} \mathrm{Re}-\mathrm{P} 2045$ and ${ }^{88} \mathrm{Y}$-DOTATOC is shown in Figure 2. At $4 \mathrm{~h}$ after injection, the levels of ${ }^{188} \mathrm{Re}-$ $\mathrm{P} 2045$ in the tumor were $9.8 \% \mathrm{ID} / \mathrm{g}$. At $24 \mathrm{~h}$, the tumor retained roughly two thirds of the radioactivity $(6.6 \% \mathrm{ID} / \mathrm{g})$ observed at $4 \mathrm{~h}$. In contrast, ${ }^{188} \mathrm{Re}-\mathrm{P} 2045$ cleared rapidly from the blood such that the tumor-to-blood ratios increased from 83 to 289 at 4 and $24 \mathrm{~h}$, respectively (Supplemental Table 3). The highest radioactivity in the ${ }^{188}$ Re-P2045 groups was observed in the tumor. There was roughly twice as much radioactivity in the tumors as in the kidneys at $4 \mathrm{~h}$ after injection. In contrast, the level of ${ }^{88}$ Y-DOTATOC in the kidneys was higher than the level in the tumors.

Scintigraphy of 3 representative AR42J mice after an intravenous injection of ${ }^{188} \mathrm{Re}-\mathrm{P} 2045$ (9.25 MBq of $\left.{ }^{188} \mathrm{Re}-\mathrm{P} 2045\right)$ is shown in Figure 3. Three minutes after injection, the bladder was visible along with the core blood volume. Eight hours after injection, the tumor and kidneys were visible and by $24 \mathrm{~h}$ after injection the radioactivity was predominantly located in the tumor.

The biodistribution of ${ }^{188} \mathrm{Re}-\mathrm{P} 2045$ in the tumor, blood, kidneys, and gut after multiple doses of ${ }^{188} \mathrm{Re}-\mathrm{P} 2045$ in the therapeutic arm of the study is shown in Table 3 . The radioactivity in the tumor and tissues of mice receiving multiple doses of ${ }^{188}$ Re-P2045

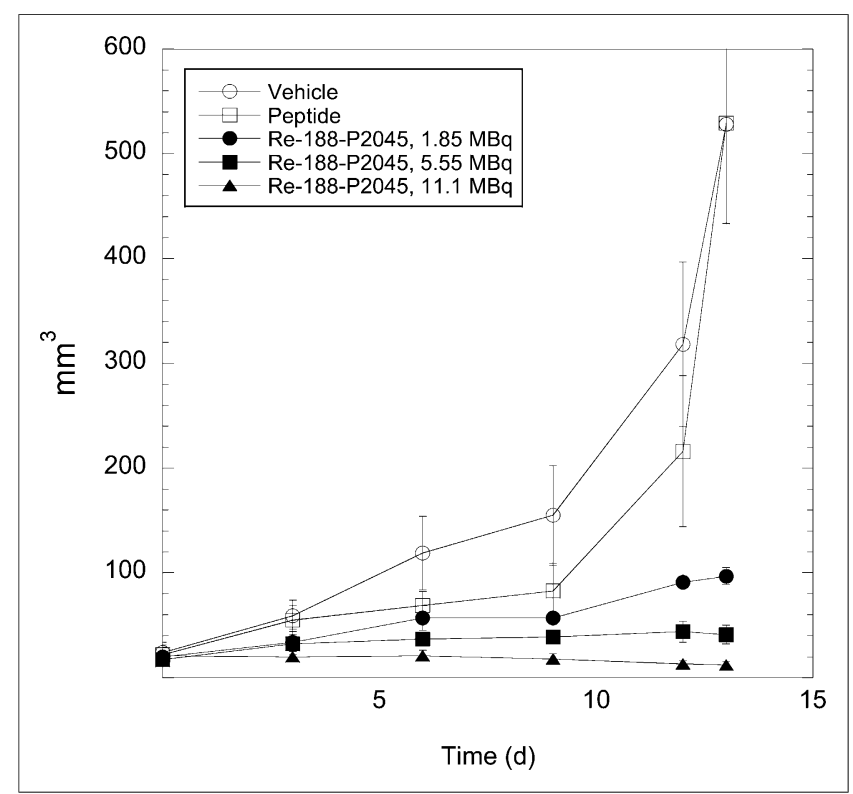

FIGURE 1. AR42J tumor volume $\left(\mathrm{mm}^{3}\right)$ with ${ }^{188} \mathrm{Re}-\mathrm{P} 2045$, compared with P2045 (peptide) and vehicle (mock eluate) control treatment. 


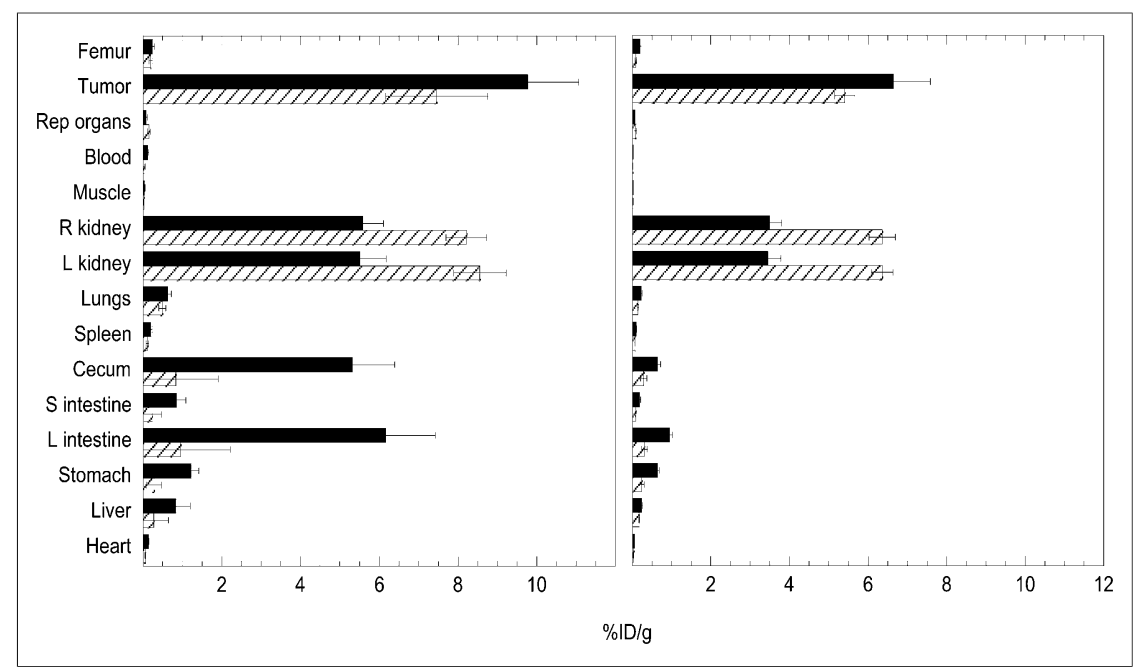

FIGURE 2. Biodistribution of ${ }^{188} \mathrm{Re}-\mathrm{P} 2045$ and ${ }^{88} \mathrm{Y}$-DOTATOC in AR42J tumor xenograft mice. Mice were injected with $9.25 \mathrm{MBq}$ of ${ }^{188} \mathrm{Re}$-P2045 (black bars) or $22.2 \mathrm{MBq}$ of ${ }^{88} \mathrm{Y}$-DOTATOC intraperitoneally (striped bars). Mice were sacrificed at 4 (left) and 24 (right) hours after injection, and tissues were collected and counted for radioactivity. Data are mean \pm SEM. $\mathrm{L}=$ large; $\mathrm{S}=$ small. groups, the radioactivity in the tumor was roughly 2 times higher than that in the kidneys and there were relatively small amounts retained in the gut.

\section{Clinical Observations, Necropsy, Hematology, and Histopathology}

${ }^{188}$ Re-P2045 was well tolerated, and adverse clinical findings were not observed in any of the ${ }^{188}$ Re-P2045 study groups. There were no significant differences in mean animal weights, and the organ-tobody weight ratios remained in the range of historic data for healthy untreated mice (15). No macroscopic abnormalities were observed during necropsy. No abnormal histopathology was noted in any tissues. As expected, undifferentiated tumor cells typical of the AR42J tumor were observed in all tumor sections, and there was no significant difference in the percentage of necrosis in any of the groups tested.

The clinical chemistry and hematology was not different from mice that received a single dose. The tumor uptake of ${ }^{188} \mathrm{Re}-\mathrm{P} 2045$ in study groups receiving 6 doses of ${ }^{188} \mathrm{Re}-$ P2045 over $16 \mathrm{~d}$ was $10.2,10.3$, and $10.4 \% \mathrm{ID} / \mathrm{g}$ in the low-, medium-, and high-dose groups, respectively. In all ${ }^{188} \mathrm{Re}-\mathrm{P} 2045$

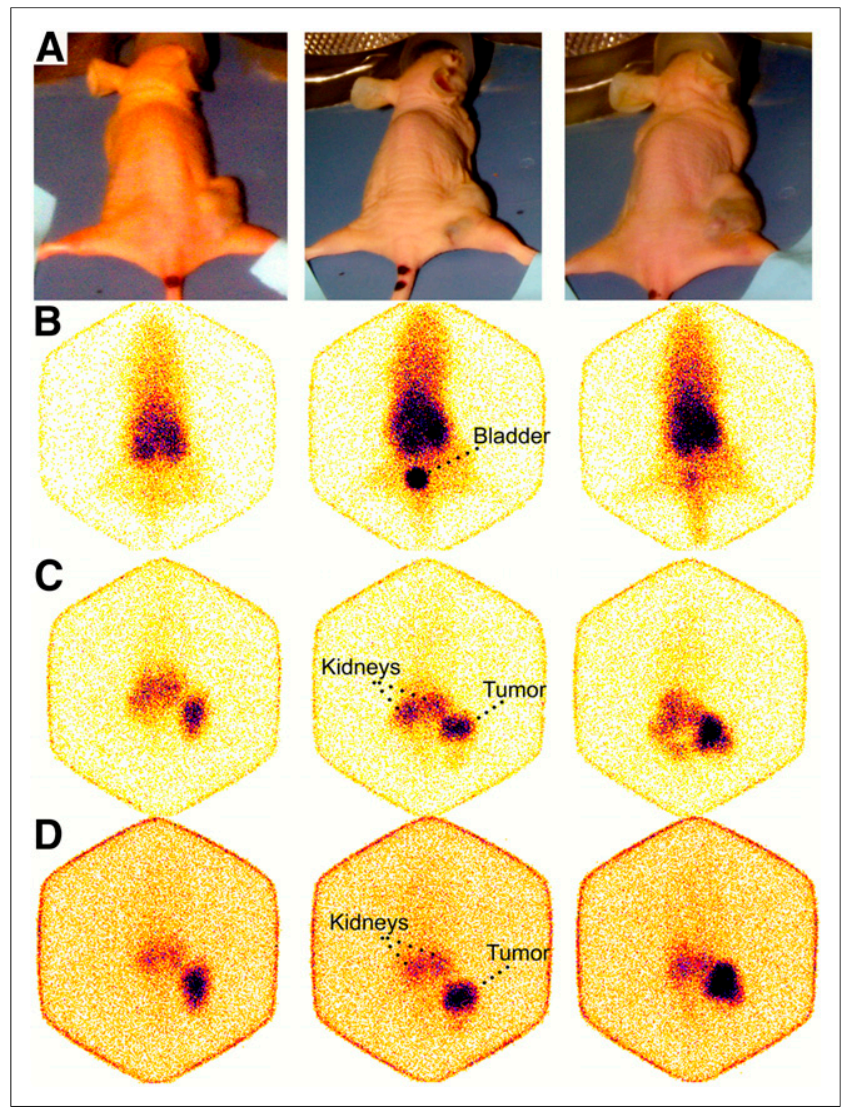

FIGURE 3. Scintigraphy of AR42J tumor xenograft mice injected with $9.25 \mathrm{MBq}$ of ${ }^{188} \mathrm{Re}-\mathrm{P} 2045$. Three individual mice bearing AR42J tumor xenografts on their right flank $(A)$ and corresponding scintigraphic images at $3 \mathrm{~min}(\mathrm{~B}), 8 \mathrm{~h}(\mathrm{C})$, and $24 \mathrm{~h}(\mathrm{D})$ after injection. results are shown in Supplemental Table 3. The percentage of neutrophils in the ${ }^{188}$ Re-P2045 treatment groups were elevated severalfold, compared with the vehicle control group $(P<$ 0.01). All other hematologic parameters were unchanged in the ${ }^{188}$ Re-P2045 treatment groups. In addition, the clinical chemistry biomarkers of renal function, blood urea nitrogen, and creatinine were unchanged in the ${ }^{188} \mathrm{Re}-\mathrm{P} 2045$ groups, compared with vehicle controls.

\section{DISCUSSION}

The current study demonstrates that ${ }^{188} \mathrm{Re}-\mathrm{P} 2045$ inhibits tumor growth in a model of pancreatic cancer. Two controls were used, 1 with free peptide and 1 with decayed generator eluate. There was a 22-fold increase in tumor growth by study day 16 in the mock eluate control group, and free peptide did not inhibit tumor growth. In comparison, the intravenous administration of ${ }^{188} \mathrm{Re}-\mathrm{P} 2045$ once every $3 \mathrm{~d}$ for $16 \mathrm{~d}$ resulted in a dose-related delay in tumor growth in the low- and mid-dose groups of 2- and 5-fold, respectively, compared with the first day of dosing. In the high-dose group, tumor growth was completely inhibited by ${ }^{188}$ Re-P2045 treatment. In fact, the mean tumor volume decreased steadily in the high-dose group over the course of treatment, although this decrease was not statistically significant. After the last dose of ${ }^{188}$ Re-P2045 was administered, tumor volumes in the high-dose group were measured over time with no additional dosing to assess the duration of the therapeutic effect. An increase in mean tumor volume was not observed until $12 \mathrm{~d}$ after the last dose was given, suggesting a long-lived therapeutic affect.

${ }^{188}$ Re-P2045 was safe and well tolerated in all dose groups. No mortality or abnormal behavior, body weights, organ weights, or histology were observed in the ${ }^{188} \mathrm{Re}-\mathrm{P} 2045$ groups. Clinical chemistries were not different between ${ }^{188} \mathrm{Re}-\mathrm{P} 2045$-treated and vehicle-treated mice. A small but statistically significant increase in the percentage of circulating neutrophils was observed in all ${ }^{188} \mathrm{Re}-\mathrm{P} 2045$ treatment groups, possibly due to the activation of neutrophils in response to tumor cell apoptosis induced by ionizing radiation (16).

${ }^{188}$ Re-P2045 cleared rapidly from the blood and nontumor tissues and paralleled that of the blood clearance. In contrast, ${ }^{188} \mathrm{Re}-\mathrm{P} 2045$ 
TABLE 3

Biodistribution of ${ }^{188}$ Re-P2045 in AR42J Rat Pancreatic Tumor Xenograft Nude Mice After 6 Doses of ${ }^{188}$ Re-P2045 (Groups 3, 4, and 5)

\begin{tabular}{lccc}
\hline \multirow{2}{*}{ Tissue } & \multicolumn{2}{c}{ Tissue uptake of ${ }^{188}$ Re-P2045 at $3 \mathrm{~h}$ after injection } \\
\cline { 2 - 4 } & Low dose $(1.85 \mathrm{MBq})$ & Mid dose $(5.55 \mathrm{MBq})$ & High dose $(11.1 \mathrm{MBq})$ \\
\hline Tumor & $10.2 \% \mathrm{ID} / \mathrm{g}$ & $10.3 \% \mathrm{ID} / \mathrm{g}$ & $10.4 \% \mathrm{ID} / \mathrm{g}$ \\
Blood & $0.177 \% \mathrm{ID} / \mathrm{g}$ & $0.116 \% \mathrm{ID} / \mathrm{g}$ & $0.098 \% \mathrm{ID} / \mathrm{g}$ \\
Kidney & $4.93 \% \mathrm{ID} / \mathrm{g}$ & $3.78 \% \mathrm{ID} / \mathrm{g}$ & $4.06 \% \mathrm{ID} / \mathrm{g}$ \\
Gastrointestinal tract & $6.01 \% \mathrm{ID}$ & $4.96 \% \mathrm{ID}$ & $4.47 \% \mathrm{ID}$ \\
Tumor-to-blood & 57.6 & 88.8 & 105 \\
Tumor-to-kidney & 2.07 & 2.73 & 2.54 \\
\hline ID $=7.4 \mathrm{MBq}$ of ${ }^{188} \mathrm{Re}-\mathrm{P} 2045$. & & & \\
\hline
\end{tabular}

cleared slowly from the tumor. The tumor-to-blood ratios were 83 and 289 at 4 and $24 \mathrm{~h}$ after a single dose. Gamma camera images and biodistribution studies demonstrated that most of the radioactivity was localized within the tumor xenograft. This result was confirmed in biodistribution studies. It is likely that receptor-ligand internalization is responsible for the delayed clearance of ${ }^{188} \mathrm{Re}-\mathrm{P} 2045$ from tumors $(17,18)$. Although difficult to demonstrate in vivo, ${ }^{188} \mathrm{Re}-\mathrm{P} 2045$ is internalized after binding to human SSTR2 transfected into HEK-293 cells in vitro $(17,19)$. It follows that P2045 is likely an SSTR agonist because only agonists are internalized (20).

G-protein-coupled receptors desensitize after prolonged exposure to agonists (21). Downregulation of SSTR has been observed in tumors exposed to SSTA (22). Receptor desensitization results in a decreased number of receptors on the cell surface and may cause a decrease in ${ }^{188} \mathrm{Re}-\mathrm{P} 2045$ in tumors after repeated doses. To test this possibility, the radioactivity in the tumors of animals receiving a single dose of ${ }^{188} \mathrm{Re}-\mathrm{P} 2045$ was compared with tumors in the study animals that had received multiple doses of ${ }^{188} \mathrm{Re}-\mathrm{P} 2045$. The radioactivity in all tumors was roughly the same, suggesting that either desensitization did not occur at the doses administered or that the SSTR had resensitized during the 3-d dosing interval (23).

The exposure of kidneys to peptide radiotherapeutic agents is a dose-limiting factor in clinical studies (24). Radiolabeled peptides are mainly excreted via the kidneys and are partly reabsorbed in the renal proximal tubules leading to kidney retention. High radiation dose to the kidneys can lead to kidney failure; therefore, it is important to minimize the kidney retention of radiotherapeutic peptides (25). Structural modifications to the chelating portion of depreotide were made to produce a library of peptides with low kidney and high tumor retention. P2045 was chosen from this library for its favorable biodistribution characteristics in SSTR2expressing murine xenograft models. The murine kidney retention of radiolabeled P2045 was roughly 25-fold lower and the tumor uptake 4-fold higher than that of depreotide (14). Importantly, markers of renal function, including blood urea nitrogen and creatinine, were normal in the ${ }^{188} \mathrm{Re}-\mathrm{P} 2045$ treatment groups. Furthermore, kidney histopathology was normal in the ${ }^{188} \mathrm{Re}-\mathrm{P} 2045$ treatment groups. The high tumor retention coupled with low kidney exposure makes ${ }^{188} \mathrm{Re}-\mathrm{P} 2045$ a promising cancer therapeutic candidate.

The AR42J tumor xenograft model was chosen for its SSTR density (14). However, the AR42J tumor originates from rat pancreatic tissue. To determine whether this model was predictive of ${ }^{188} \mathrm{Re}-\mathrm{P} 2045$ binding to human SSTR, the binding affinity of ${ }^{185 / 187}$ Re-P2045 for SSTR was compared in membranes prepared from rat AR42J and human NCI-H69 tumor cells expressing predominantly SSTR2. Because the $\mathrm{IC}_{50}$ values were similar (3), the AR42J model was considered representative of human SSTR2-expressing tumors.

${ }^{177} \mathrm{Lu}$-DOTATATE is considered the current gold standard for the treatment of SSTR2-expressing tumors (26). Although we conducted no ${ }^{177} \mathrm{Lu}$-DOTATATE studies in our laboratory, the important comparators are published $(26,27)$. The binding affinity of ${ }^{177}$ Lu-DOTATATE for human SSTR2-transfected cell membranes was reported to be $1.5 \pm 0.4 \mathrm{SEM} \mathrm{nM} \mathrm{(27),} \mathrm{and} \mathrm{the} \mathrm{binding}$ affinity of ${ }^{177} \mathrm{Lu}$-DOTATATE for rat SSTR2 expressed in AR42J membranes was $0.21-0.23 \mathrm{nM}(28)$. In contrast, ${ }^{185 / 187} \mathrm{Re}-\mathrm{P} 2045$ bound more avidly to human H69 SSTR2 $(0.23 \pm 0.1 \mathrm{nM}$, Table 2) and less avidly to rat SSTR2 expressed in AR42J tumor membranes $(0.43 \pm 0.19$, Table 2$)$. These studies suggest that ${ }^{188} \mathrm{Re}-\mathrm{P} 2045$ binds with approximately 7-fold-higher avidity to human SSTR2 and with 2-fold-lower avidity to rat SSTR than ${ }^{177} \mathrm{Lu}$-DOTATATE. It follows that the AR42J tumor model might favor higher tumor levels of ${ }^{177} \mathrm{Lu}$-DOTATATE but clinical studies might favor tumor uptake of ${ }^{188}$ Re-P2045. Levels of radioactivity in the AR42J tumor were similar for both agents (Fig. 2) (26).

The physical characteristics of ${ }^{188} \mathrm{Re}$ are superior to those of ${ }^{177} \mathrm{Lu} .{ }^{188} \mathrm{Re}$ is inexpensively produced from an on-site ${ }^{188} \mathrm{~W} /{ }^{188} \mathrm{Re}$ generator $(29,30)$. The generator is shipped to hospitals where its shelf-life is several months, and the specific activity of the eluted ${ }^{188} \mathrm{Re}$ is greater than $25.9 \mathrm{MBq} / \mathrm{mL}(30)$. Additionally, ${ }^{188} \mathrm{Re}$ has a decay half-life of $17 \mathrm{~h}$ that is ideal for radiotherapy because its radioactive decay parallels the biologic clearance of ${ }^{188} \mathrm{Re}-\mathrm{P} 2045$. Furthermore, the same ${ }^{188} \mathrm{Re}$ chelator can be used to complex ${ }^{99 \mathrm{~m}} \mathrm{Tc}$ to P2045 for imaging (5), and both P2045-chelated products distribute similarly in the body (14). Because different SSTAs have different signature affinities for each of the SSTR subtypes (2), the ideal scenario is to use the same peptide for diagnosis as for radiotherapy. In contrast, ${ }^{177} \mathrm{Lu}$ must be shipped on-demand from a facility with a cyclotron and has a half-life of $6.65 \mathrm{~d}(26)$.

\section{CONCLUSION}

This study demonstrates that ${ }^{188} \mathrm{Re}-\mathrm{P} 2045$ inhibited tumor growth in a model of SSTR2-expressing pancreatic cancer in a dose-related fashion. The agent was well tolerated in all treatment groups and cleared rapidly from the blood and nontarget tissues. Levels of ${ }^{188} \mathrm{Re}-\mathrm{P} 2045$ were low in the kidneys, and parameters of kidney 
function were normal. Levels of ${ }^{188} \mathrm{Re}-\mathrm{P} 2045$ were high in the tumor, and levels were not diminished by multiple doses. Collectively, these data indicate that ${ }^{188} \mathrm{Re}-\mathrm{P} 2045$ is a promising therapeutic candidate for the treatment of cancers expressing SSTR2. ${ }^{188}$ Re-P2045, also known as Tozaride (Andarix Pharmaceuticals), is currently in active development and has recently received orphan drug designation in the United States for small cell lung and pancreatic cancer.

\section{DISCLOSURE}

The costs of publication of this article were defrayed in part by the payment of page charges. Therefore, and solely to indicate this fact, this article is hereby marked "advertisement" in accordance with 18 USC section 1734. Christopher P. Adams owns and Carol A. Nelson and Christopher P. Adams own stock options in Andarix Pharmaceuticals, a company developing ${ }^{188} \mathrm{Re}-\mathrm{P} 2045$ for clinical use. No other potential conflict of interest relevant to this article was reported.

\section{ACKNOWLEDGMENTS}

This publication is dedicated to Dr. Michael T. Azure who died in 2013. He is greatly missed by his friends and colleagues. We thank Dr. Trenton Schoeb for the histopathology evaluations.

\section{REFERENCES}

1. Reubi JC. Peptide receptors as molecular targets for cancer diagnosis and therapy. Endocr Rev. 2003;24:389-427.

2. Reubi JC, Schonbrunn A. Illuminating somatostatin analog action at neuroendocrine tumor receptors. Trends Pharmacol Sci. 2013;34:676-688.

3. Eden PA, Taylor JE. Somatostatin receptor subtype gene expression in human and rodent tumors. Life Sci. 1993;53:85-90.

4. Starkey JR, Pascucci EM, Drobizhev MA, Elliott A, Rebane AK. Vascular targeting to the SST2 receptor improves the therapeutic response to near-IR twophoton activated PDT for deep-tissue cancer treatment. Biochim Biophys Acta General Subjects. 2013;1830:4594-4603.

5. Chalabi M, Duluc C, Caron P, et al. Somatostatin analogs: does pharmacology impact antitumor efficacy? Trends Endocrinol Metab. 2014;25:115-127.

6. O'Byrne KJ, Carney DN. Radiolabelled somatostatin analogue scintigraphy in oncology. Anticancer Drugs. 1996;7(suppl 1):33-44.

7. Grewal RK, Dadparvar S, Yu JQ, et al. Efficacy of Tc-99m depreotide scintigraphy in the evaluation of solitary pulmonary nodules. Cancer J. 2002;8:400-404.

8. Ho RJY, Chien J. Trends in translational medicine and drug targeting and delivery: new insights on an old concept-targeted drug delivery with antibody-drug conjugates for cancers. J Pharm Sci. 2014;103:71-77.

9. Edelman MJ, Clamon G, Kahn D, Magram M, Lister-James J, Line BR. Targeted radiopharmaceutical therapy for advanced lung cancer: phase I trial of rhenium Re188 P2045, a somatostatin analog. J Thorac Oncol. 2009;4:1550-1554.

10. Cremonesi M, Ferrari M, Paganelli G, et al. Radiation protection in radionuclide therapies with ${ }^{90}$ Y-conjugates: risks and safety. Eur J Nucl Med Mol Imaging. 2006;33:1321-1327.

11. Enger SA, Hartman T, Carlsson J, Lundqvist H. Cross-fire doses from beta-emitting radionuclides in targeted radiotherapy: a theoretical study based on experimentally measured tumor characteristics. Phys Med Biol. 2008;53:1909-1920.
12. Okuwaki K, Kida M, Mikami T, et al. Clinicopathologic characteristics of pancreatic neuroendocrine tumors and relation of somatostatin receptor type $2 \mathrm{~A}$ to outcomes. Cancer. 2013;119:4094-4102.

13. Pearson DA, Lister-James J, McBride WJ, et al. Somatostatin receptor-binding peptides labeled with technetium-99m: chemistry and initial biological studies. J Med Chem. 1996;39:1361-1371.

14. Cyr JE, Pearson DA, Wilson DM, et al. Somatostatin receptor-binding peptides suitable for tumor radiotherapy with Re-188 or Re-186: chemistry and initial biological studies. J Med Chem. 2007;50:1354-1364.

15. Charles River. Technical Bulletin. Wilmington, MA: Charles River Laboratories; 1999.

16. Lorimore SA, Coates PJ, Scobie GE, Milne G, Wright EG. Inflammatory-type responses after exposure to ionizing radiation in vivo: a mechanism for radiationinduced bystander effects? Oncogene. 2001;20:7085-7095.

17. Waser B, Tamma ML, Cescato R, Maecke HR, Reubi JC. Highly efficient in vivo agonist-induced internalization of sst2 receptors in somatostatin target tissues. J Nucl Med. 2009;50:936-941.

18. Marchese A, Trejo J. Ubiquitin-dependent regulation of $\mathrm{G}$ protein-coupled receptor trafficking and signaling. Cell Signal. 2013;25:707-716.

19. Rogers BE, Chaudhuri TR, Reynolds PN, Della Manna D, Zinn KR. Non-invasive gamma camera imaging of gene transfer using an adenoviral vector encoding an epitope-tagged receptor as a reporter. Gene Ther. 2003;10:105-114.

20. Cescato R, Schulz S, Waser B, et al. Internalization of sst2, sst3, and sst5 receptors: effects of somatostatin agonists and antagonists. J Nucl Med. 2006; 47:502-511.

21. Lefkowitz RJ, Rajagopal K, Walen EJ. New roles for beta-arrestins in cell signaling: not just for seven-transmembrane receptors. Mol Cell. 2006;24:643-652.

22. Froidevaux S, Hintermann E, Török M, Mäcke HR, Beglinger C, Eberle AN. Differential regulation of somatostatin receptor type 2 (sst 2) expression in AR42J tumor cells implanted into mice during octreotide treatment. Cancer Res. 1999;59:3652-3657.

23. Koper JW, Hofland LJ, van Koetsveld PM, den Holder F, Lamberts SW. Desensitization and resensitization of rat pituitary tumor cells in long-term culture to the effects of somatostatin analogue SMS 201-995 on cell growth and prolactin secretion. Cancer Res. 1990;50:6238-6242.

24. Vegt E, de Jong M, Wetzels JF, et al. Renal toxicity of radiolabeled peptides and antibody fragments: mechanisms, impact on radionuclide therapy, and strategies for prevention. J Nucl Med. 2010;51:1049-1058.

25. Bodei L, Pepe G, Paganelli G. Peptide receptor radionuclide therapy (PRRT) of neuroendocrine tumors with somatostatin analogues. Eur Rev Med Pharmacol Sci. 2010;14:347-351.

26. Maina TNB, Nikolopoulou A, Petrou C, Cordopatis P. Evaluation of peptides labeled with beta emitting radionuclides for receptor targeted radiotherapy of malignant tumours. In: Agency IAE, ed. Comparative Evaluation of Therapeutic Radiopharmaceuticals. Vol. 458. Vienna, Austria: International Atomic Energy Agency; 2007:87-102.

27. Cescato R, Waser B, Fani M, Reubi JC. Evaluation of ${ }^{177}$ Lu-DOTA-sst2 antagonist versus ${ }^{177} \mathrm{Lu}$ DOTA-sst2 agonist binding in human cancers in vitro. $\mathrm{J}$ Nucl Med. 2011;52:1886-1890.

28. Chinol MC, Choi SJ. Optimization of Labelling Conditions and Cell Binding Assay for 177-Lu-Dotatate: Comparative Evaluation of Therapeutic Radiopharmaceuticals. Vol. 458. Vienna, Austria: International Atomic Energy Agency; 2007:163-168.

29. Jeong JM, Knapp FF Jr. Use of the Oak Ridge National Laboratory tungsten-188/ rhenium-188 generator for preparation of the rhenium-188 HDD/lipiodol complex for trans-arterial liver cancer therapy. Semin Nucl Med. 2008;38:S19-S29.

30. Guhlke S, Beets AL, Oetjen K, Mirzadeh S, Biersack H-J, Knapp FF. Simple new method for effective concentration of ${ }^{188} \mathrm{Re}$ solutions from alumina-based ${ }^{188} \mathrm{We} /$ ${ }^{188}$ Re generator. J Nucl Med. 2000;41:1271-1278. 